\title{
DEFINIÇÃO DE ZONAS DE INTERESSE METROPOLITANO COMO SUBSÍDIO PARA O PLANEJAMENTO AMBIENTAL NA REGIÃO METROPOLITANA DE BELO HORIZONTE
}

\author{
Rodrigo Machado Fernandes Leitão \\ Universidade Federal de Minas Gerais, Instituto de Geociências \\ rmf.leitao@gmail.com \\ Guilherme Augusto Pereira Malta \\ Universidade Federal de Juiz de Fora, Instituto de Ciências Humanas \\ guilherme.malta@ich.ufif.br \\ Frederico Azevedo Lopes \\ Universidade Federal de Minas Gerais, Instituto de Geociências \\ fredericolopes@ufmg.br
}

\section{RESUMO}

A proposta de Macrozoneamento da Região Metropolitana de Belo Horizonte (RMBH), ocorrida entre 2013-2015, deu legitimidade à intervenção e regulação do poder público sobre a dinâmica territorial, intermediando conflitos e conciliando interesses, por meio da delimitação de Zonas de Interesse Metropolitano (ZIM). Deste modo, busca-se estabelecer conjuntos de uso e apropriação do território conforme suas características intrínsecas, tendências e necessidades, associando formas de apropriação do território às dinâmicas atuais e futuras. Neste contexto, este trabalho tem por objetivo a delimitação e definição de parâmetros que possibilitem a identificação de áreas, ou zonas, com similitudes quanto às suas características ambientais, especialmente em relação à necessidade deconservação/preservação, recuperação e uso, que subsidiem a delimitação das ZIM. Foi utilizado a metodologia relativa aos processos de zoneamento ambiental, disponibilizada pelo Ministério do Meio Ambiente e a técnica de análise multicritérios, visando determinar o grau de semelhança e a compatibilidade entre as áreas previamente sugeridas no processo de macrozoneamento e aquelas identificadas neste estudo. Conclui-se que, diante do significativo número de áreas degradadas e/ou precariamente protegidas, torna-se fundamental a efetivação do planejamento, gestão e manejo das áreas verdes e de proteção ambiental visando à promoção da sustentabilidade socioeconômica da população que reside na $\mathrm{RMBH}$.

Palavras-chave: Zoneamento. Análise Multicritério. Planejamento Ambiental.

\section{DEFINITION OF METROPOLITAN INTEREST AREAS AS A TOOL FOR ENVIRONMENTAL PLANNING IN THE METROPOLITAN REGION OF BELO HORIZONTE}

\begin{abstract}
The macro zoning proposal of the Metropolitan Region of Belo Horizonte (RMBH), occurred between 2013-2015, legitimizedthe public government intervention and regulation over territorial dynamics, intermediating conflicts and reconciling interests, by demarkingMetropolitan Interest Areas (ZIM). Thus, it is tried to establish sets of use and territory appropriation according to its intrinsic characteristics, trends and requirements, linking forms of territorial appropriation to current and future dynamics. In this context, this work aims to delimit and definestandards to allow the identification of areas, or zones, with similarities according their environmental characteristics, especially related to the requirements ofconservation/preservation, recoveringand use, that support the ZIM's delimitation. Therefore, were used the methodology current used by the National Environmental Ministryfor environmental zoning process and multicriteria analysis, aiming to determinelevels of similarity and compatibilitybetween areas previously proposed during the macro zoning process and those ones identified in this study.It is concluded that, due to the significant number of degraded and/or precariously protected areas, it is fundamental to carry out the planning and management of green areas and environmentally protected, promoting the socioeconomic sustainability of the population residing in the $\mathrm{RMBH}$.
\end{abstract}

Keywords: Macro zoning. Multi-criteria analysis. Environmental planning.

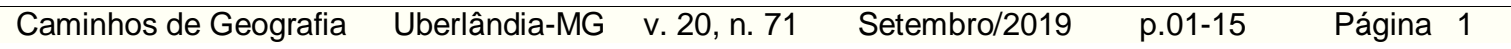




\section{INTRODUÇÃO}

O planejamento ou ordenamento do espaço podeser observado desde a antiguidade, com a consideração de aspectos ambientais, preceitos religiosos, estéticos e conforto no processo de ocupação e organização do território (SANTOS, 2004). Entretanto, a relação do homem com seu ambiente tem gerado impactos massivos, especialmente ao longo dos últimos séculos (GOUDIE, 2013).

Neste contexto, os processos de urbanização desordenados tem gerado diversos impactos ambientais (KOOP e VAN LEEUWEN 2017)associadosa alterações na dinâmica hidrológica (IPCC, 2014; SERRAO-NEWMAN et al., 2017), degradação na qualidade das águas superficiais (TUCCI, 2008; LOPES et al., 2019),redução da recarga de sistemas aquíferos (FELLIPE et al., 2011) e alterações climáticas locais (MACHADO e ASSIS, 2016).Além disso, o referido processo de "metropolização" não foi acompanhado, em níveis adequados, pelo atendimento da população urbana por serviços de saneamento básico. Com as deficiências no setor de saneamento básico, os planos e projetos de controle e/ou combate à degradação ambiental, tendem a tornar-se pouco eficazes (LOPES et al., 2003), expondo especialmente a populaçãoresidente nas periferias e subúrbios (ex.: LEFEBVRE, 1999) a riscos de natureza hidrológica, geológica e sanitária (ex.: EHP, 1996; ZUCARELLI et al., 2010; KOOP \&VAN LEEUWEN,2017).

Dentre os desafios do planejamento urbano territorial (ex.: MASCARELLI e KLEIMANN, 2017), destaca-se a construção de um instrumento que possibilite a reestruturação territorial e 0 controle do uso e ocupação do solo nos grandes centros urbanos. Assim, o Macrozoneamento da Região Metropolitana de Belo Horizonte (RMBH) foi formulado a partir de um processo participativo de debates das questões metropolitanas, com a representação de diversos segmentos da sociedade (poder público e iniciativa privada).O processo de Macrozoneamento (MZ-RMBH) busca ser uma diretriz para conduzir as ações dos sujeitos metropolitanos no sentido da construção de uma Região Metropolitana de Belo Horizonte mais dinâmica, igualitária e sustentável(UFMG, 2014a).

A concretização da referida proposta, traz como consequência uma maior intervenção e regulação do poder público sobre a dinâmica territorial, intermediando conflitos e acomodando interesses. Neste sentido, a proposição das ZIMs - Zonas de Interesse Metropolitano buscam estabelecer conjuntos de uso e apropriação do território conforme suas características intrínsecas, tendências e necessidades, associando formas de apropriação do território às dinâmicas atuais e futuras, especificamente na identificação de áreas prioritárias à conservação/preservação, recuperação e uso (UFMG, 2014b).

Deste modo, o trabalho visadelimitar Unidades Ambientais Homogêneas (UAHs) na RMBH, cuja representatividade denota características similares, de áreas específicas, no que diz respeito à congruência de formas de relevo, uso do solo e cobertura vegetal, semelhantes.Nesse sentido, esta proposta se destina a apontar, do ponto de vista ambiental, quais porções da RMBH se assemelham quanto às categorias e estágios de qualidade ambiental - seja por características próprias (naturais) existentes e inerentes às áreas, seja por força de instrumentos legais de proteção - ou ambos, pertinentes à forma de planejamento que se preocupe com as formas de uso, recuperação e conservação/preservação.

\section{MATERIAL E MÉTODOS}

\section{LOCALIZAÇÃO DA ÁREA DE ESTUDO}

A região metropolitana de Belo Horizonte (Figura 1), criada pela Lei Complementar Federal n.․ 14/73(BRASIL, 1973), e regulamentada pelas Leis Complementares n..-88/2006 e n.․ 89/2006do Estado de Minas Gerais (MINAS GERAIS 2006a; 2006b), consiste na terceira maior aglomeração urbana do país, com uma população total de 5873841 habitantes (IBGE, 2016). 
Figura1 - Localização da RMBH.

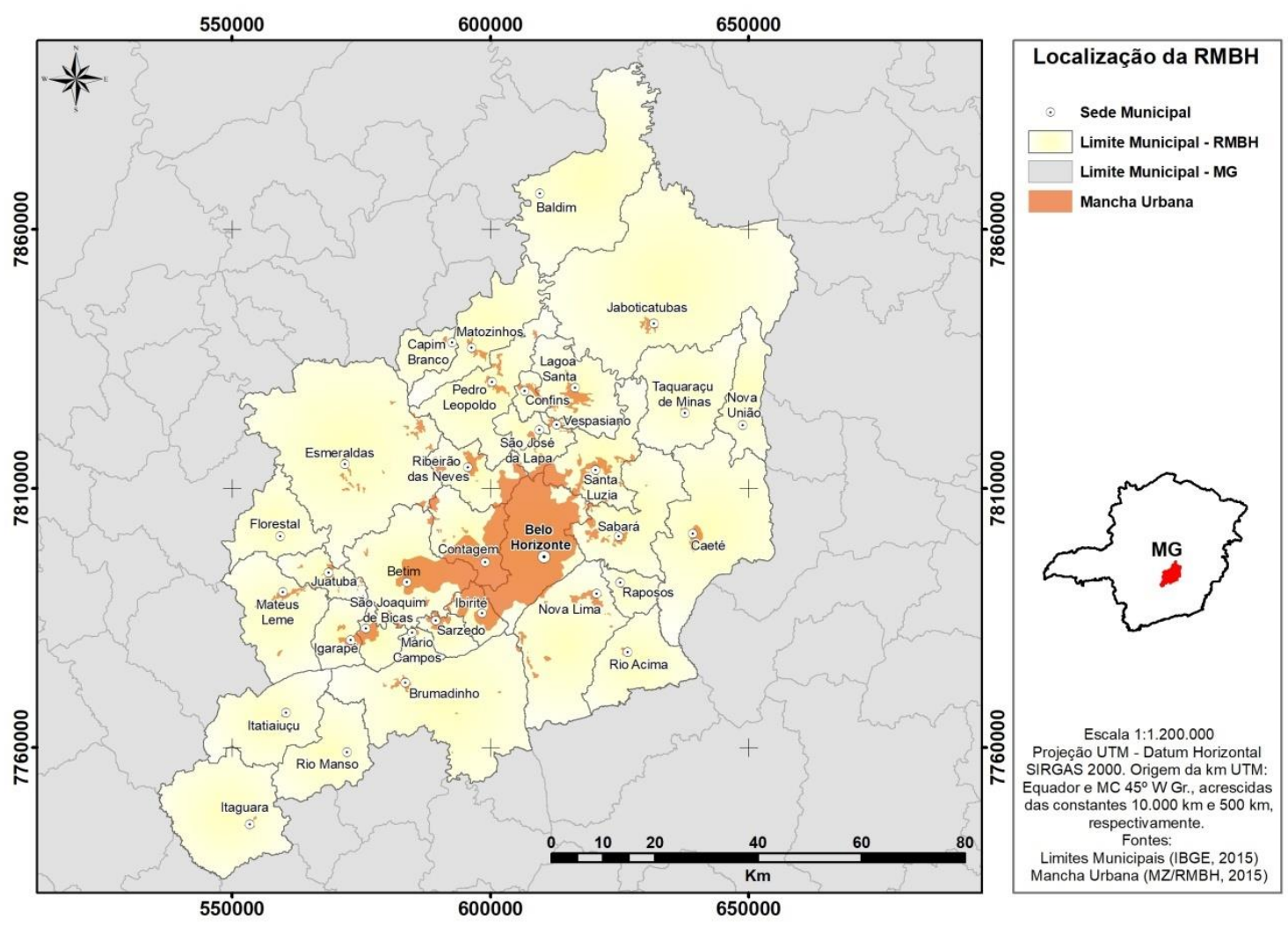

A RMBH era originalmente composta por 14 municípios: Belo Horizonte, Betim, Caeté, Contagem, Ibirité, Lagoa Santa, Nova Lima, Pedro Leopoldo, Raposos, Ribeirão das Neves, Rio Acima, Sabará, Santa Luzia e Vespasiano (BRASIL, 1973). Atualmente é formada por 34 municípios, abrangendo uma área total de $331 \mathrm{Km}^{2}$ (MINAS GERAIS, 2006b).

O Macrozoneamento Metropolitano é um marco normativo para a gestão do uso e ocupação do solo em nível supra municipal, que busca consolidar a reestruturação territorial metropolitana e servir de referencial para a revisão dos Planos Diretores (PDs) municipais e demais planos e instrumentos de planejamento (UFMG, 2014a). Neste cenário, a delimitação das ZIM referia-se àdelimitação de territórios da RMBHem que o interesse metropolitano fosse preponderante sobre o interesse local (UFMG, 2014b).

\section{PROCEDIMENTOS METODOLÓGICOS}

A partir do acesso ao conjunto de dados e informações ambientais acumulados ao longo de todo o processo de elaboração do Macrozoneamento da $\mathrm{RMBH}$, em especial em sua fase de diagnóstico (Produtos 1 a 3), foram realizadas diversas análises em ambiente SIG (Sistema de informações Geográficas), apoiadas, sobretudo, por critérios ambientais, que subsidiassem a delimitação de zonas homogêneas.

Deste modo, foram definidas três categorias temáticas: a) áreas preferenciais para conservação/preservação; b) áreas preferenciais para recuperação; e c) áreas preferenciais para utilização. Para cada uma das categorias mencionadas, conforme descrito na metodologia a seguir, foram escolhidos critérios e valores específicos que embasaram as avaliações e análises ao fim desse estudo.

A análise multicritérios, amplamente utilizada em estudos relacionados ao diagnóstico e planejamento ambiental (e.g. BEINAT e NIJKAMP, 1998; MALCZEWSKI, 2004; CHEN et al., 2001; CARVALHO et al., 2013), visa desde a definição de áreas mais adequadas para 
implantação de empreendimentos até a análise de risco ambiental, consiste em uma ferramenta matemática, que embasada em diversos critérios, permite comparar diferentes cenários ou alternativas (ROY, 1996). O objetivo do uso desta ferramenta é auxiliar a tomada de decisão em um contexto que envolve informações complexas e muitos agentes e atores envolvidos, bem como, conflitos de interesses, sendo, portanto, fundamental a sistematização das respostas.

O caminho metodológico seguido no presente estudo tem por embasamento principal passos ora delineados pelo Ministério da Integração Nacional, por meio do PBA 14 - programa socioambiental de conservação e uso de porções do território, voltado para a identificação e delimitação de Unidades Ambientais Homogêneas (UAH). As UAH podem ser caracterizadas como:

\begin{abstract}
"compartimentos paisagísticos (...) que possuem características semelhantes, ou seja, locais em que os atributos dos terrenos (a configuração morfológica, a cobertura vegetal e os usos e ocupações atuais da terra) constituem um padrão espacial facilmente identificável" (BRASIL, 2005b).
\end{abstract}

Tal metodologia abrange, portanto,num primeiro momento, a construção de um cenário que resulte num mosaico de unidades espaciais, resultante de combinações específicas entre parâmetros ambientais, gerando unidades de paisagem identificáveis por características específicas e sustentadas por sistemas ambientais funcionais.Posteriormente, definidas as UAH, passa-se então para a análise dos componentes ambientais subjacentes à cada área, tendo como finalidade produzir uma Matriz de Interação resultado da inter-relação dos componentes ambientais - ou critérios ambientais, e seu entorno.

Primeiramente foram definidas as categorias "relevo" e "uso do solo e cobertura vegetal" para todo o território da RMBH como base para a construção das UAH. Para a categoria relevo, obedecendo a escala de 1:250.000, foram identificadas 5 classes associadas às formas do mesmo, a saber: Carste, Pediplano, Topo Aguçado, Topo Convexo e Topo Tabular. Tal representação cartográfica do relevo da $\mathrm{RMBH}$ foi compilada a partir de dados oriundos do IBGE, bem como do Projeto RADAM Brasil (BRASIL,1978).

A categoria uso e ocupação do solo resulta de extensos e cuidadosos processos de mapeamentos desenvolvidos ao longo dos anos de 2014 e 2015, visto que sua representação satisfaz a escala de 1:50.000 onde foram utilizadas imagens de satélite Landsat/lkonos/SPOT, bem como compilações oriundas de estudos associados à região. Nas tabelas $(1 ; 2)$ abaixo, é possível reconhecer a dimensão espacial e sua representatividade em termos absolutos no que diz respeito às porções ocupadas por cada classe, de cada critério, no território da RMBH.

Tabelas 1 - Categorias de Relevo/Forma.

\begin{tabular}{lc}
\hline Forma & Área( $\left.\mathbf{K m}^{2}\right)$ \\
\hline Carste & 521,06 \\
Pediplano & 113,94 \\
Topo Aguçado & 968,5 \\
Topo Convexo & 7027,24 \\
Topo Tabular & 844,11 \\
Total & 9474,85 \\
\hline
\end{tabular}

Tabela 2 - Classes de mapeamento adotadas.

\begin{tabular}{cc}
\hline Classe & Área( $\left.\mathbf{K m}^{2}\right)$ \\
\hline Antrópico & 4402,84 \\
Natural & 5072,01 \\
Total & 9474,85 \\
\hline
\end{tabular}


Cabe ressaltar que, ao longo do processo de criação das UAH, foi determinado que a menor unidade mapeável, para a escala do estudo - 1:50.000, resultaria de áreas superiores a 6,25 hectares, conforme abordado pelo Manual de Uso da Terra do IBGE (IBGE, 2006).

O próximo passo metodológico seguiu de forma a avaliar as UAH sobre uma perspectiva ampliada, de forma que diferentes critérios ambientais fossem trazidos para a análise, com o intuito de compor um cenário ambiental para cada recorte territorial, possibilitando avaliar e justificar a presença de cada UAH nas categorias propostas (BRASIL, 2005).

Os critérios escolhidospara composição da análise multicritério (tabela 3), baseados na importância e relevância para a conservação regional, foram caracterizados conforme suas respectivas fontes de dados e levantamentos realizados ao longo do Projeto de Macrozoneamento da RMBH (UFMG, 2014a). Para a elaboração destes critérios foram realizados os procedimentos descritos abaixo, a partir do levantamento de informações e dadosconforme adotados no Projeto de Macrozoneamento, por meio da crescente participação e interação com as populações locais e os vários técnicos nos níveis municipal e estadual.

Tabela 3 - Valoração dos critérios.

\begin{tabular}{|c|c|c|c|}
\hline Critério & Tipo & Nota & Peso \\
\hline \multirow{3}{*}{ Unidades de Conservação } & UC Estadual/Federal/Municipal - Uso Sustentável & 1 & 1 \\
\hline & RPPN & 2 & 1 \\
\hline & UC Estadual/Federal/Municipal - Proteção Integral & 99 & 1 \\
\hline $\begin{array}{c}\text { Área de entorno de cavidades } \\
\text { naturais }\end{array}$ & Abrangência & 3 & 1 \\
\hline $\begin{array}{l}\text { Áreas de Preservação Permanente } \\
\text { (APP) }\end{array}$ & Abrangência & 3 & 1 \\
\hline $\begin{array}{l}\text { Propostas de criação de unidades de } \\
\text { conservação - em análise pelo poder } \\
\text { público }\end{array}$ & Abrangência & 2 & 1 \\
\hline \multirow{3}{*}{ Cobertura vegetal } & Antrópica & 1 & 1 \\
\hline & Natural & 3 & 1 \\
\hline & Inexistente & 0 & 1 \\
\hline \multirow{2}{*}{$\begin{array}{l}\text { Áreas prioritárias para a conservação } \\
\text { - Atlas da Biodiversidade de MG }\end{array}$} & Fauna ou Flora & 2 & 1 \\
\hline & Fauna e Flora & 3 & 1 \\
\hline $\begin{array}{c}\text { Áreas tombadas no nível municipal, } \\
\text { estadual e federal }\end{array}$ & Abrangência & 99 & 1 \\
\hline $\begin{array}{l}\text { Zonas de amortecimento de unidades } \\
\text { de conservação }\end{array}$ & Abrangência & 1 & 1 \\
\hline \multirow{3}{*}{ Enquadramento de Corpos d'água } & Classe Especial e 1 & 3 & 1 \\
\hline & Classe 2 & 2 & 1 \\
\hline & Classe 3 & 1 & 1 \\
\hline
\end{tabular}

No primeiro critério utilizado, Unidades de Conservação, os dados foram obtidos e atualizados por meio de informações repassadas por órgãos como IEF (2015), SEMAD (2015), ICMBio (2015) e secretarias de meio ambiente de Belo Horizonte e demais municípios da RMBH. Obedecendo as categorias de UC's estabelecidas pelo Sistema Nacional de Unidades de 
Conservação (SNUC) (BRASIL, 2000), as unidades de proteção integral e de uso sustentável, associadas as áreas de proteção a nível federal. No caso estadual foram consideradas as Áreas de Proteção Especial (APE's) estadual (APE's) e municipal, visando ampliar as informações adquiridas no Plano Diretor de Desenvolvimento Integrado da RMBH (UFMG, 2011), tendo em vista que novas áreas foram criadas. Cabe ressaltar, que para as unidades de uso sustentável, em virtude do alto grau de intervenção humana observado, concomitante à sua efetividade de proteção, foi atribuído nota mínima (1). As unidades de proteção integral não foram pontuadas por já possuírem marco legal e efetivo de proteção. As RPPN's, por corresponderam a áreas que possuem respaldo legal, porém, com menor nível de restrição se comparadas às últimas, porém mais eficientes que as primeiras, receberam nota 2.

A presença de zonas de amortecimento das unidades de conservação, sendo estas relacionadas aos Parques Estaduais do Sumidouro e Rola Moça, foram pontuadas com nota 1, uma vez que estas exercem influência positiva para o meio ambiente. Desse modo, tais áreas contribuem diretamente para o manejo sustentável e conservação do entorno das UC's as quais estão associadas.

As cavidades e seu entorno, outro critério utilizado, teve como embasamento a base cartográfica fornecida pelo Centro Nacional de Pesquisa e Conservação de Cavernas (CECAV, 2015) e referencial conceitual associado (BRASIL, 2008; MMA, 2009). Considerou-se, assim, que as cavidades subterrâneas possuem diferentes graus de relevância definidos por seus atributos geológicos, hidrológicos, ecológicos, biológicos, paleontológicos, cênicos, históricoculturais e socioeconômicos. Baseado nessa realidade, tais áreas foram definidas como de extrema relevância para a composição de uma leitura ambiental da $\mathrm{RMBH}$, especialmente no que tange à forma de ocupação e uso do seu território.

A existência de áreas de preservação permanente (APP) ao longo da $\mathrm{RMBH}$ foi mais um critério utilizado, que segundo o Novo Código Florestal Brasileiro (BRASIL, 2012). Essa informação indica áreas de grande relevância para a preservação ambiental na RMBH e em decorrência disso recebeu nota 3.

Baseado nas informações do Sistema Estadual de Meio Ambiente (SISEMA, 2015) e Instituto Estadual de Florestas (IEF, 2015), foram identificados corredores ecológicos e áreas previstas para o estabelecimento de unidades de conservação. Localizadas, preponderantemente, no Vetor Norte da RMBH, as áreas previstas, em sua maioria como unidades de conservação de proteção integral. As áreas analisadas nesse estudo correspondem àquelas ainda em processo de aprovação pelo poder público e, portanto, não representam uma proposta já consolidada. Assim, apesar de seu status indefinido, porém reconhecido seu valor ambiental, a elas foi atribuída a nota 2 .

A categoria cobertura vegetal resulta da compilação das informações levantadas por meio do mapeamento de uso e ocupação do solo. Este critério contemplou a existência ou não de cobertura vegetal, sendo à porção antropizada, tais como pastagens, agricultura, silvicultura, dentre outros, atribuída a nota 1. Para as áreas de cobertura natural, como fragmentos florestais, formações campestres ou savânicas, atribuiu-se a nota máxima (3). Para as áreas desprovidas de vegetação, tais como solos expostos, áreas urbanizadas, dentre outras, não foram atribuídas notas.

As áreas prioritárias para conservação da fauna e da flora foram levantadas a partir do Atlas da Biodiversidade, elaborado pela Fundação Biodiversitas (DRUMMOND et al., 2005), e apontam recortes específicos de significativa relevância ambiental no território metropolitano. Tal critério delimita áreas com diferentes prioridades para conservação de ecossistemas e populações vegetais e animais. Dado isto, as áreas que possuem, de forma conjunta, prioridade para a conservação de fauna e flora, receberam pontuação máxima. Aquelas cuja territorialidade aponta para a prioridade de conservação, ora de fauna, ora de flora, receberam nota 2. 
Por fim, o enquadramento de bacias hidrográficas, critério de extrema relevância para a condição ambiental da $\mathrm{RMBH}$, sobretudo no panorama atual, teve suas notas atribuídas conforme os níveis de qualidade exigidos quando do gerenciamento dos recursos hídricos de cada bacia (MINAS GERAIS, 2008; IGAM, 2014). Assim, tanto sejam maiores os esforços de conservação, bem como seu grau de fragilidade - classes de enquadramento Especial e 1, maior a nota atribuída, o que denota, portanto, maior necessidade de proteção.

A partir da definição e caracterização dos critérios utilizados, bem com suas notas e pesos, foram desenvolvidas operações espaço-relacionais com o intuito de determinar as porções comuns entre cada UAH e seus respectivos componentes ambientais, como pode ser visto conceitualmente na figura abaixo.

Figura 2 - Operaçõesespaço-relacionais.

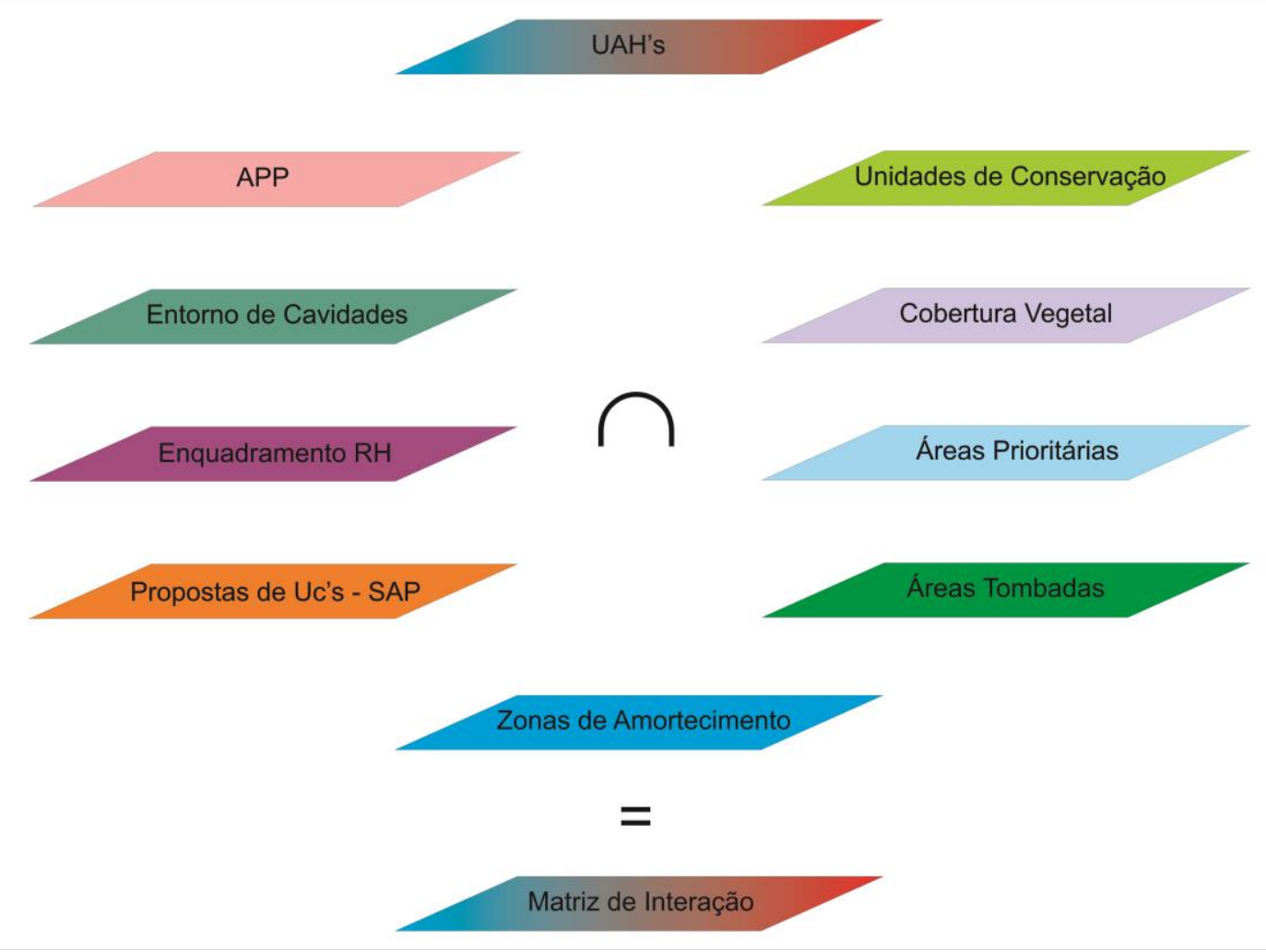

De posse dos resultados, estes em forma de uma camada nomeada como Matriz de Interação, foram consideradas duas formas de categorização dos resultados. A primeira categorização dos resultados considerou a atribuição de notas e pesos correspondentes a cada critério, como visto acima, sua inter-relação com demais critérios, procedimentos aritméticos e estatísticos associados à Matriz de Interação, gerando áreas preferencias, assim denominadas:Áreas Preferenciais para Utilização; Áreas Preferenciais para Recuperação e Áreas Preferenciais para Conservação.A segunda categorização buscou refinar o primeiro processo de modo a rever os valores limite, agora de acordo com as características ambientais específicas de cada área preferencial, de forma a permitir uma melhor compreensão de sua abrangência e importância.

\section{RESULTADOS E DISCUSSÃO}

\section{PROPOSIÇÃO DAS UNIDADES AMBIENTAIS HOMOGÊNEAS (UAH)}

A partir da correlação entre as categorias "relevo" e "uso do solo e cobertura vegetal" foram criados 10 tipos de UAHs, sendo eles: Carste-Antrópico (CA), Carste-Natural (CN), Pediplano- 
Antrópico (PA); Pediplano-Natural (PN), Topo Aguçado-Antrópico (TaA), Topo Aguçado-Natural (TaN), Topo Convexo-Antrópico (TcA), Topo Convexo-Natural (TcN), Topo Tabular-Antrópico (TtA) e Topo Tabular-Natural (TtN). Por meio das 10 categorias de UAHs geradas chega-se à conformação de um panorama espacial da RMBH composto de um mosaico de unidades espaciais (Figura 3 ). Dessas combinações obteve-se, um total de 3483 unidades, dispostas no conjunto das 10 categorias de UAHs identificadas (Tabela 4).

Figura 3 - Unidades Ambientais Homogêneas (UAH).

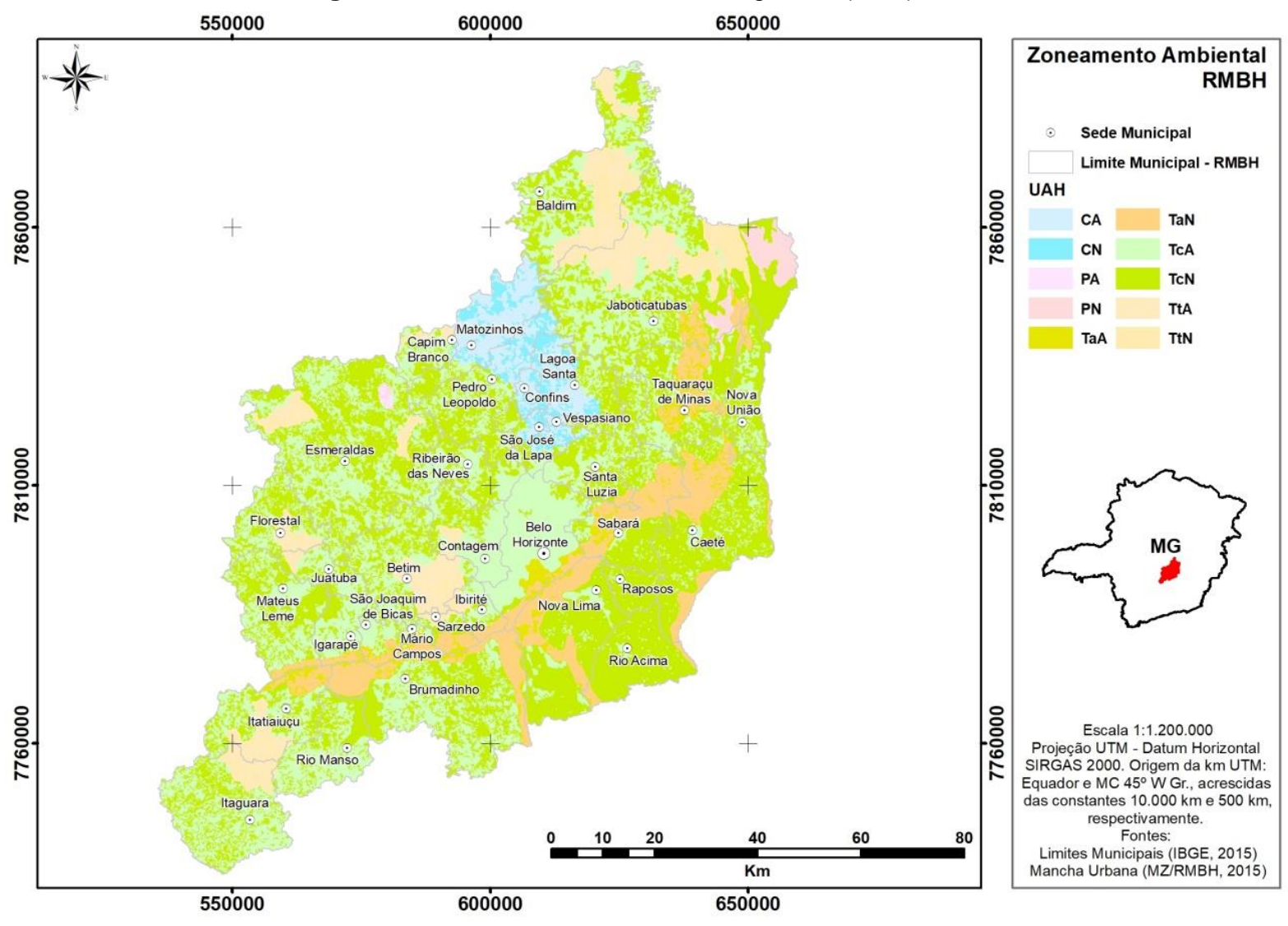

Tabela 4 - Número de unidades por tipo de UAH.

\begin{tabular}{lccc}
\hline Forma & Classe & UAH & $\mathbf{N}^{\circ}$ de unidades \\
\hline \multirow{2}{*}{ Carste } & Antrópico & CA & 52 \\
& Natural & CN & 106 \\
\hline \multirow{2}{*}{ Pediplano } & Antrópico & PA & 11 \\
& Natural & PN & 10 \\
\hline \multirow{2}{*}{ Topo Aguçado } & Antrópico & TaA & 258 \\
& Natural & TaN & 52 \\
\hline \multirow{2}{*}{ Topo Convexo } & Antrópico & TcA & 1494 \\
& Natural & TcN & 1186 \\
\hline \multirow{2}{*}{ Topo Tabular } & Antrópico & TtA & 112 \\
& Natural & TtN & 202 \\
\hline Total & & & 3483
\end{tabular}




\section{AVALIAÇÃO DO POSICIONAMENTO DAS UAHS E PROPOSTA DE ZONEAMENTO AMBIENTAL}

Os resultados obtidos possibilitaram a divisão de toda extensão territorial da RMBH em 3 categorias. Por meio do cálculo de valores por critérios atribuídos ${ }^{1}$ alcançou-se uma nota final, que determinou o posicionamento de cada UAH considerando-se as categorias ( $\left.\begin{array}{lll}1 & \text { a } & 3\end{array}\right)$ mencionadas. Assim, tem-se, então, a dispersão dos mesmos em faixas de valores associados às classes pré-estabelecidas, conforme a metodologia, e agrupadas conforme os limites determinados pelo gráfico abaixo (Figura 4). Neste caso, a distribuição de frequência dos valores ao longo da curva demonstra como a mesma simboliza as diferenças entre áreas com relevantes atributos ambientais.

Deste modo, é possível notar que a média mais frequente se associa às áreas onde a soma das notas de cada critério alcançam o valor " 6 ", ou seja, representa a média resultado da maior repetição de valores calculados pela Matriz de Interação. Assim como temos tal média, é notável também que os pontos de inflexão da curva alcançam as somas "4" e "9" - mais precisamente " 4,25 " e " 9,38 ", sendo estes os limites determinados pela variação das frequências, ou desvio padrão - "2,56". Assim, as classes ora mencionadas se distribuem estatisticamente abrangendo os valores de 1 a 4 para áreas preferenciais para utilização, indicando parcelas significativamente adensadas e antropizadas do território, de 5 a 9 para áreas preferenciais para recuperação e de 10 a 18 para áreas preferenciais para conservação existentes na RMBH (Figura 5).

Figura 4 - Gráfico de frequências dos resultados da Matriz de Interação.

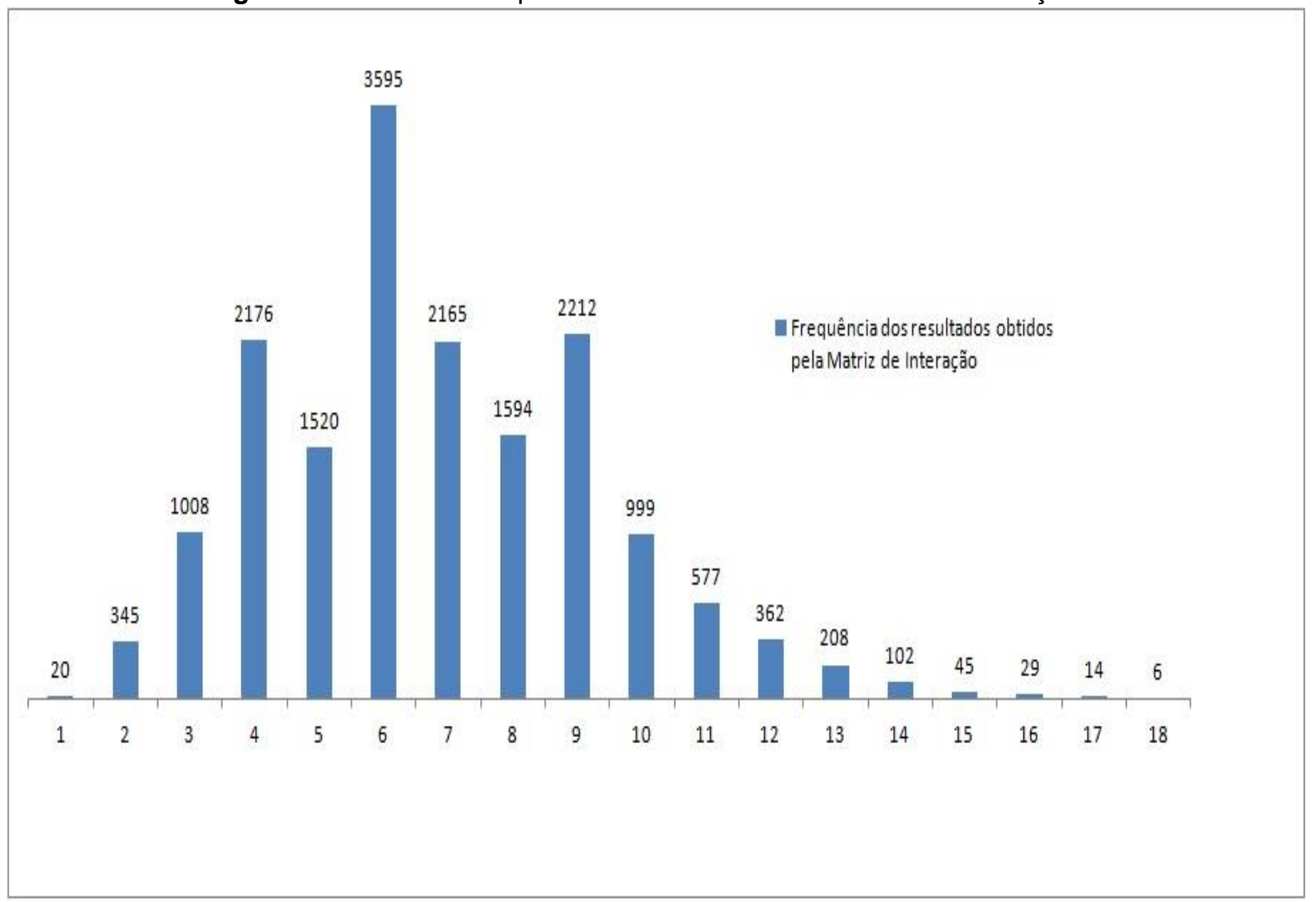

${ }^{1}$ Cabe mencionar, contudo, que os valores (99) referentes às áreas tombadas e às unidades de conservação de proteção integral não foram considerados na análise estatística, já que comprometeriam a distribuição de frequência dos resultados. 
Figura 5 - Áreas preferenciais RMBH.

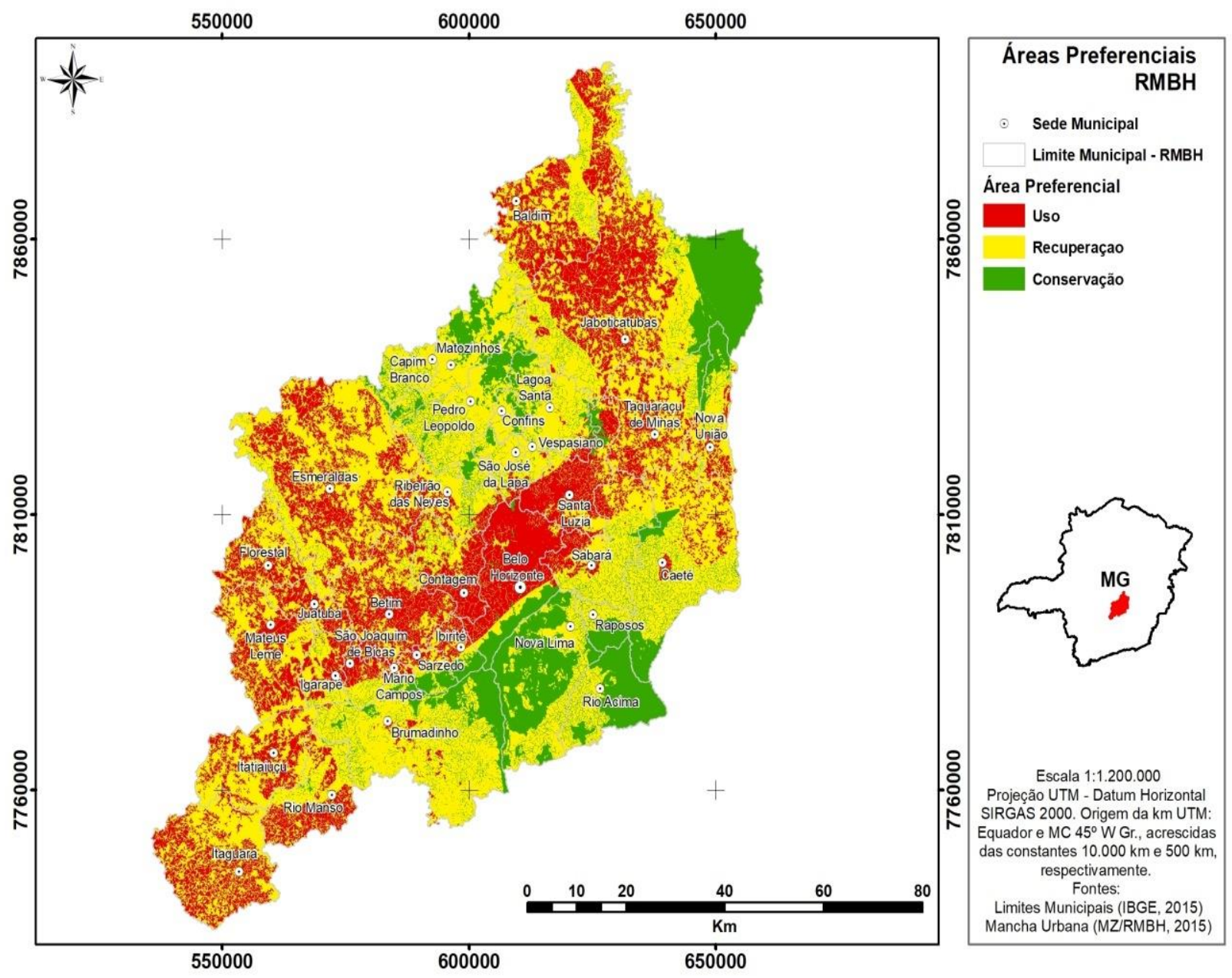

Como mencionado, para este estudo não bastou uma análise estatística dos resultados, visto que a existência de informações, bem como sua qualidade, resultado dos levantamentos realizados ao longo do MZ-RMBH, permite aprofundar tal análise e subdividir as classes ora arbitradas, de forma a esmiuçar seus componentes e, então, sua importância. Assim, as áreas preferenciais foram subdivididas em um tipo específico de zonas, onde o resultado compõe 0 mapa de zoneamento ambiental da RMBH (Figura 5).

Os resultados obtidos possibilitaram a divisão de toda extensão territorial da RMBH em 5 categorias (uso; uso restrito; recuperação; preservação; conservação) relativas às especificidades do território. Tal subdivisão está ancorada nas relações geoambientais entre os componentes e indica com maior rigor suas características no que tange ao planejamento e uso do solo na RMBH. O procedimento adotado para a elaboração do zoneamento consistiu, portanto, em uma redistribuição estatística dos valores encontrados para as áreas preferenciais, cujos intervalos de transição foram recategorizados de acordo com as especificidades territoriais, considerando agora duas novas classes: uso restrito e preservação. 
Figura 6 - Zoneamento Ambiental RMBH.

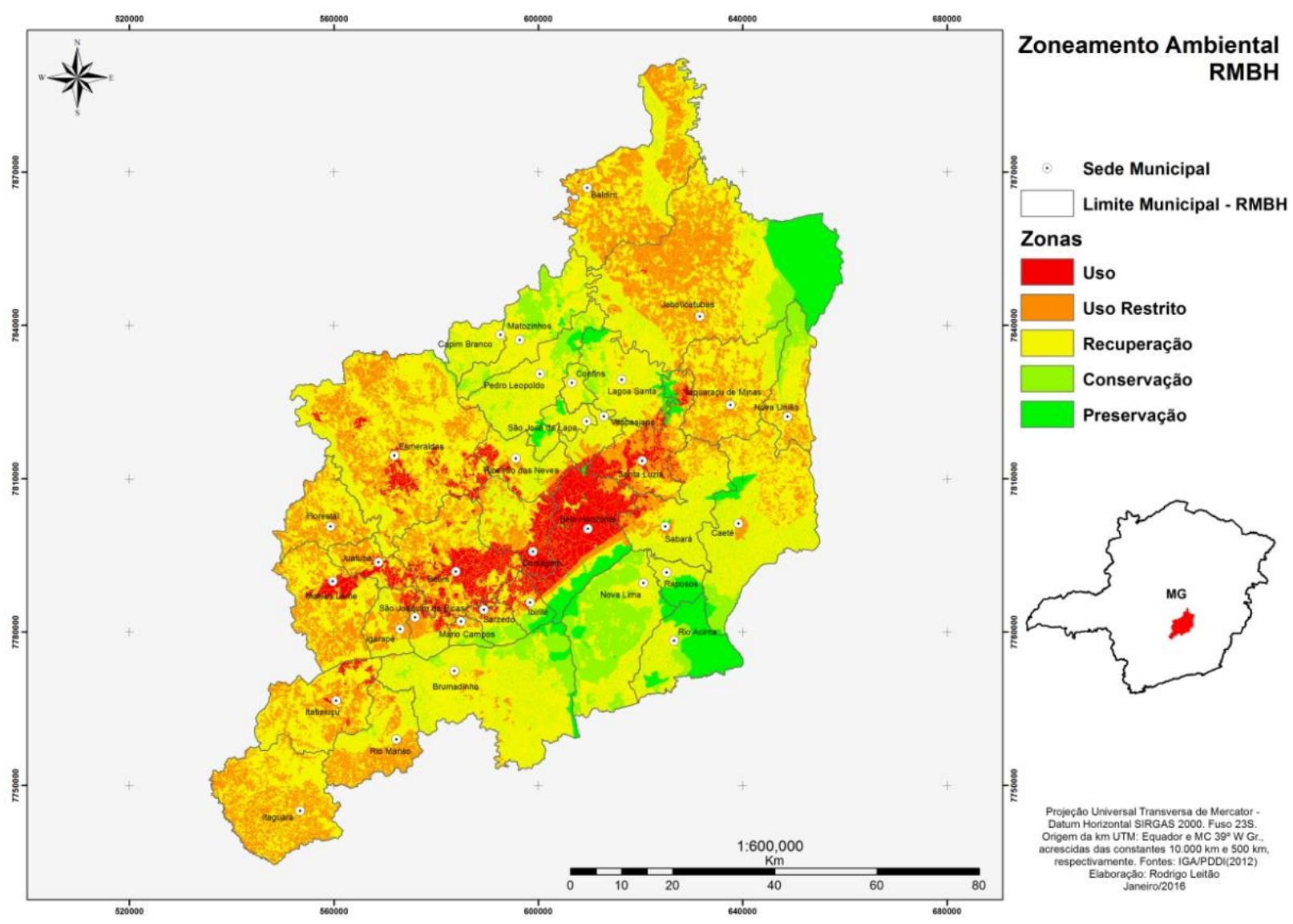

A análise do Zoneamento ambiental da RMBH (Figura 6) indica que a zona definida como de Uso (gradiente de notas final 1 e 2) corresponde a áreas de expressivoadensamento demográfico e urbanização, que caracterizam-se como de uso essencialmente antrópico, marcadas por vegetação completamente antropizada e pouca restrição quanto ao uso dos recursos hídricos (enquadramento de classe 3).

Os resultados correspondentes à Zona de Uso Restrito (gradiente de notas final 3 e 4) indicam a possibilidade de utilização e consolidação das atividades antrópicas com ressalvas, devido a critérios específicos relacionados ao enquadramento de corpos d'água, resquícios de vegetação natural e poucas áreas de preservação permanente presentes, esparsamente, nesta zona. Além disso, destaca-sea presença de unidades de conservação e respectivaszonas de amortecimento, com atenção para uma RPPN e uma unidade de conservação de uso sustentável, bem como áreas prioritárias para a conservação de fauna e flora.

A Zona de Recuperação, por sua vez, remete às UAHs onde foi identificado um grande potencial ambiental, porém, em grande parte, com presença de componentes degradados ou pouco protegidos. A efetividade de vegetação natural nesta zona, por exemplo, representa cerca de $65 \%$ de sua área total. Dos $35 \%$ restantes, cerca de $72 \%$ se referem às áreas cuja vegetação natural foi substituída por pastagens, agricultura ou silvicultura. As demais áreas se encontram com usos consolidados de forma que não mais existe vegetação natural associada às mesmas. Há que se ressaltar, contudo, que a porção mais expressiva da vegetação natural consisteem o principal componente responsável por elevar a importância ambiental de tais áreas, inserindo-as nesta categoria de recuperação.

Desse modo, há que se pensar em formas de recuperação, sobretudo, dos recursos hídricos, na qual cerca de $45 \%$ na área encontram-se enquadrados nas classes 2 e 3, bem como em recuperar as zonas tampão de áreas prioritárias para a criação de unidades de conservação, 
áreas prioritárias para a conservação de fauna e flora e entorno de zonas de amortecimento. Ademais, cerca de $23 \%$ da Zona de Recuperação é composta por APP's, visto que cerca de $60 \%$ das mesmas requer intervenções voltadas para a recomposição ou recuperação de sua vegetação. É necessário abordar também que, para certos componentes ambientais, como o caso dos cursos d'água enquadrados como Especial e 1, a recuperação de seu entorno implica também na, interceptação e tratamento de efluentes, dentre outros, de forma a se assegurar o atendimento ao enquadramento proposto.

A Zona de Conservação, determinada a partir da releitura do gradiente constante entre os valores10 e 17, denota, em contraposição à anterior, necessidade de maior atenção com o que se refere à conservação dos componentes ambientais existentes, mas também, e da mesma forma, a recuperação de áreas adjacentes aos mesmos. Como exemplo, é possível abordar a vegetação natural com predominância de $89 \%$ da mesma, seguida de $8 \%$ de vegetação antropizada e $3 \%$ de cobertura vegetal inexistente. Neste caso, nota-se a presença de uma condição ambiental, no mínimo, favorável, pois a vegetação natural, expoente nesta zona, traz consigo uma série de relações que vão desde aspectos ligados ao clima e variações de temperatura até condições essenciais para a manutenção da fauna e flora na RMBH. Apesar de apresentar certa fragmentação, tais recortes, se conservados, juntamente com os demais, recuperados, podem levar a uma condição ambiental ótima, visto que grande parte dessa fragmentação se dá ao nível de zona, mas em menor escala se trazida para o nível hierárquico de componente ambiental.

Diferentemente da Zona de Recuperação, as APP's compõem cerca de $55 \%$ do total, uma vez que $87 \%$ desse recorte é composto por áreas com vegetação natural, cuja diferença responde por $13 \%$ de APP's a serem recuperadas e/ou restauradas. No que diz respeito aos recursos hídricos, esta zona se apresenta, como para os demais componentes, com qualidade positiva, porém menos expressiva, visto que cerca de $63 \%$ do seu território é enquadrado como classe Especial ou 1, enquanto as demais áreas como classes 2 e 3 . Neste caso, como mencionado anteriormente, é necessária atenção especial quanto à necessidade de recuperação da qualidade das águas dos recursos hídricos locais, visto a potencialidade local advinda da soma de seus atributos. Outros pontos importantes a serem destacados nesta zona se fazem presentes na existência e necessidade de conservação de cavidades naturais subterrâneas, visto que as mesmas recebem tratamento especial por força de legislação específica, mas também por comportarem riquezas ambientais inestimáveis para a dinâmica local e regional. Da mesma forma, a presença de unidades de conservação (federais, estaduais e municipais), deve ser destacada em consonância com propostas de conservação e áreas prioritárias para conservação de fauna e flora.

A Zona de Preservação, composta pelos resultados com gradiente compreendidos acima da nota 17, agora incluídas as porções com notas iniciais superiores a 99, apresenta características ambientais extremamente relevantes. Classes de enquadramento mais exigentes, fragmentos de vegetação naturais combinados a áreas prioritárias para a conservação de fauna e flora, concomitantemente às unidades de conservação de proteção integral, áreas tombadas, áreas de preservação permanente e fragmentos contidos em zona de amortecimento, possivelmente acarretariam uma melhor qualidade ambiental de toda a RMBH. A combinação desses componentes ambientais enseja não somente proteção, mas sobretudo preservação, pois trata de ambientes com especificidades e peculiaridades combinadas de forma única, onde a sinergia dos mesmos no território contribui para a manutenção das áreas verdes, não só localmente, mas para toda a RMBH.

\section{CONSIDERAÇÕES FINAIS}

A contínua pressão antrópica sobre as áreas verdes, áreas rurais e ambientalmente protegidas, como as áreas de mananciais de abastecimento da RMBH, é efeito direto do modelo vigente e predatório de crescente expansão da mancha urbana em direção às periferias distantes. Dada essa complexa realidade, é urgente equilibrar a delimitação de reservas naturais com a de áreas verdes e especialmente, de recuperar áreas com significativo potencial ambiental e que segundo os resultados apresentados, mostram-se como degradadas ou pouco protegidas. 
A extensa pesquisa e diagnóstico iniciados por meio doPDDI da RMBH, evidencia a necessidade de se ampliar os espaços públicos, novas centralidades, as áreas verdes, os parques e jardins, os equipamentos de lazer e recreação, com vistas a combater: i) as desigualdades sócio-espaciais; ii) a segregação e a guetificação dos espaços urbanos; iii) a privatização dos espaços públicos.

No que compete especificamente à ampliação das áreas verdes, torna-se necessário mencionar, que por serem consideradas importantes para a qualidade ambiental urbana (obrigatórias por lei) elas atuam como um indicador em sua própria avaliação. A inexistência ou baixa incidência de áreas verdes, por exemplo, são responsáveis por alterações no microclima e causa de desconfortos térmicos, além de impactarem de forma negativa na qualidade de vida da população que as utiliza para fins recreativos e de lazer. Da mesma forma, tal lacuna indica, indiretamente, a queda da qualidade de serviços ambientais extremamente necessários à dinâmica do meio, sendo possível citar a fragmentação/retração da cobertura vegetal, a piora nas qualidades do ar e água da $\mathrm{RMBH}$, sobretudo em relação à disponibilidade quantitativa e qualitativa de recursos hídricos

A adoção de planejamento, gestão e manejo das áreas verdes e de proteção ambiental é, portanto, peça primordial para a sustentabilidade socioeconômica da população que reside na $\mathrm{RMBH}$. A delimitação de zonas que demonstram a situação ambiental atual da RMBH, com enfoque especial para a representativa extensão de áreas degradadas e/ou precariamente protegidas, assim como apresentado neste trabalho, visou contribuir para a consolidação do planejamento por meio da geração de políticas (a exemplo do projeto de Lei - PL 3.078/12) capazes de tornar o uso e ocupação do solo em maior conformidade com a gestão responsável do meio ambiente, voltada para melhoria da qualidade de vida da população metropolitana, mas também do próprio meio ambiente.

\section{REFERÊNCIAS BIBLIOGRÁFICAS}

BEINAT, E.; NIJKAMP, P. Environmental Rehabilitation: Efficiency and Effectiveness in Soil Remediation*. In: Studies in Regional and Urban Planning. 1998, v. 6. pp. 83-101.

BRASIL. Lei complementar no 14, de 8 de junho de 1973. Estabelece as regiões metropolitanas de São Paulo, Belo Horizonte, Porto Alegre, Recife, Salvador, Curitiba, Belém e Fortaleza. DOU, 1973.

BRASIL. Departamento Nacional da Produção Mineral. Projeto RADAMBRASIL. Folha AS.20. Manaus; geologia, geomorfologia, pedologia, vegetação e usopotencial da terra. Rio de Janeiro, 1978.

BRASIL. Lei nº 9.985, de 18 de julho de 2000. Regulamenta o art. 225, § 10, incisos I, II, III e VII da Constituição Federal, institui o Sistema Nacional de Unidades de Conservação da Natureza e dá outras providências. DOU, 2000.

BRASIL. Ministério da Integração. Projeto de Integração do Rio São Francisco com bacias hidrográficas do Nordeste Setentrional: Programa Básico Ambiental 14. In: Programa de Conservação e Uso do Entorno e das Águas dos Reservatórios. Brasília, 2005(a).

BRASIL. IBAMA - Instituto Brasileiro do Meio Ambiente e dos Recursos Naturais Renováveis. Termo de Referência para Elaboração do Plano Ambiental de Conservação e Uso do Entorno do Reservatório Artificial a ser formado pelo reservatório da UHE Estreito. Brasília, 2005(b).

BRASIL. Decreto 6,640. Dá nova redação aos arts. $1^{\circ}, 2^{\circ}, 3^{\circ}, 4^{\circ}$ e $5^{\circ}$ e acrescenta os arts. 5-A e 5-B ao Decreto no 99.556, de $1^{\circ}$ de outubro de 1990, que dispõe sobre a proteção das cavidades naturais subterrâneas existentes no território nacional. Brasília, 2008. BRASIL. MMA - Ministério do Meio Ambiente. Instrução normativa $\mathbf{n}^{\circ} \mathbf{2}$ de 20 de agosto de 2009. Brasília, 2009.

BRASIL. IBAMA - Instituto Brasileiro do Meio Ambiente e dos Recursos Naturais Renováveis. Licença Prévia Ambiental n³85/2010, em 13 de dezembro de 2010. Brasília, 2010. 
BRASIL. Lei no 12.651, de 25 de maio de 2012. Dispõe sobre a proteção da vegetação nativa; altera as Leis nos 6.938 , de 31 de agosto de 1981, 9.393, de 19 de dezembro de 1996, e 11.428, de 22 de dezembro de 2006; revoga as Leis nos 4.771, de 15 de setembro de 1965, e 7.754, de 14 de abril de 1989, e a Medida Provisória no 2.166-67, de 24 de agosto de 2001; e dá outras providências. DOU, 2012.

CARVALHO, J. R. M. DE.; CURI, W. F. Construção de um índice de sustentabilidade hidroambiental através da análise multicritério: estudo em municípios paraibanos / Building a index of sustainability trough hydroenvironmental multicriteria analysis: A study in municipalities of Paraíba (Br). Sociedade \& Natureza, v. 25, n. 1, 91-106. 2013. https://doi.org/10.1590/S198245132013000100008

CECAV. Centro Nacional de Pesquisa e Conservação de Cavernas. Base de dados geoespacializados das cavernas do Brasil: Minas Gerais, 2015. Disponível em: < www.icmbio.gov.br/cecav/downloads/mapas.html>. Acesso em: 10 dez. 2015.

CHEN, K.P.; BLONG, R.; JACOBSON, C. MCE-RISK: integrating multicriteria evaluation and GIS for risk decision making in natural hazards. Environmental Modelling \& Software, v. 16, n.4, p. 387-397, 2001. https://doi.org/10.1016/S1364-8152(01)00006-8

DRUMMOND, G.M. et al. Biodiversidade em Minas Gerais: um atlas para sua conservação. Belo Horizonte: Fundação Biodiversitas, 2. ed, 2005. 222.

ENVIRONMENTAL HEALTH PROJECT- EHP. Health \& environment in urban poor areas: avoiding a crisis through prevention. EHP Capsule Report. n.1, 1996.

FELLIPE, M.F.; MATOS, R.E.S.; MAGALHAES JR, A.P.; RODRIGUES, B.M.; COSTA, A.; GARCIA, R.A. Evolução da ocupação urbana das zonas preferenciais de recarga de aquíferos de Belo Horizonte-MG. Revista de Geografia - PPGEO,v.2, n.1, p.1-9, 2011.

GOUDIE, A. The human impact on the natural environment: past, present and future. Oxford: John Willey \& Sons, Seventh edition, 2013, 410p.

IBGE. Manual Técnico de Uso da Terra. 2. ed., Rio de Janeiro: IBGE, 2006.

ICMBio. Instituto Chico Mendes de Biodiversidade. Dados Geográficos/Unidades de Conservação. Disponível em: <http://www.icmbio.gov.br/portal/servicos/geoprocessamento/51menu-servicos/4004-downloads-mapa-tematico-e-dados-geoestatisticos-das-uc-s.html>.

Acessoem: 10 dez. 2015.

INTERGOVERNMENTAL PANEL ON CLIMATE CHANGE - IPCC. Freshwater Resources. In Climate Change 2014 - Impacts, Adaptation, and Vulnerability: Part A: Global and Sectoral Aspects: Working Group II Contribution to the IPCC Fifth Assessment Report (pp. 229-270). Cambridge University Press. 2014.

KOOP S.H.A.; VAN LEEUWEN, C.J. The challenges of water, waste and climate change in cities. Environment, Development and Sustainability, 19, 385-418, 2017. https://doi.org/10.1007/s10668-016-9760-4

LEFEBVRE, H. A revolução urbana. Belo Horizonte: Editora da UFMG, 1999, 178p.

LOPES, F.A.; DAVIES-COLLEY, R.; PIAZI, J.; SILVEIRA, J.S.; LEITE, A.C.; LOPES, N.I.A. Challenges for contact recreation in an urban tropical lake. Assessment by a water quality index. Environment, Development and Sustainability, 2019. https://doi.org/10.1007/s10668019-00430-4

LOPES, F.W.A.; MACEDO, D.R.; MEDEIROS, I.H.; UMBELINO, G.J.; MAGALHÃES JR, A.P. Bacias hidrográficas como unidade de análise dos processos de urbanização desordenados. $O$ caso da bacia do Córrego do Nado - Belo Horizonte/MG. Geo Uerj, n. especial, p.1985-2002, 2003.

MACHADO, L.; ASSIS, W. IMPACTOS DA EXPANSÃO URBANA NA PORÇÃO NORTE DO MUNICÍPIO DE NOVA LIMA (MG) SOBRE O CLIMA. Revista do Departamento de Geografia, n. spe, p. 115-132, 2016. https://doi.org/10.11606/rdg.v0ispe.117754 
MALCZEWSKI, J. GIS-based land-use suitability analysis: A critical overview. Progress in Planning, v.62, n.1, p.3-65, 2004. https://doi.org/10.1016/j.progress.2003.09.002

MINAS GERAIS. Deliberação Normativa Conjunta COPAM/CERH 01. Dispõe sobre a classificação e o enquadramento dos corpos d'água. Diário do Executivo - Minas Gerais, 2008.

IGAM - Instituto de Gestão de Águas de Minas Gerais (IGAM). Relatório Anual de Gestão e Situação dos Recursos Hídricos de Minas Gerais - 2014. Disponível em: <http://portalinfohidro.igam.mg.gov.br/>. Acesso em: 10 dez. 2015.

IEF. Instituto Estadual de Florestas de Minas Gerais. Sistema de áreas protegidas - Vetor Norte RMBH, 2015. Disponível em: <http://www.ief.mg.gov.br/areas-protegidas/sap-rmbh/1645unidades-de-conservacao-do-sap-vetor-norte>. Acesso em: 10 dez. 2015.

MINAS GERAIS. Lei Complementar 88, de 12/01/2006. Dispõe sobre a instituição e a gestão de região metropolitana e sobre o fundo de desenvolvimento metropolitano. Minas Gerais Diário do Executivo - 13/01/2006 (b).

MINAS GERAIS.Lei Complementar 89, de 12/01/2006. Dispõe sobre a região metropolitana de Belo Horizonte. Minas Gerais Diário do Executivo - 13/01/2006 (a).

MOSCARELLI, F.; KLEIMAN, M. Os desafios do planejamento e gestão urbana integrada no Brasil: análise da experiência do Ministério das Cidades. URBE, Rev. Bras. Gest. Urbana, v. 9, n. 2, p. 157-171, 2017. https://doi.org/10.1590/2175-3369.009.002.ao01

SANTOS, R.F. Planejamento ambiental: teoria e prática. São Paulo: Oficina de Textos, 2004, 184p.

SERRAO-NEUMANN, S.; RENOUF, M.; KENWAY, S.; LOW CHOY, D. Connecting land-use and water planning: Prospects for an urban water metabolism approach. Cities, 60, p. 13-27. 2017. https://doi.org/10.1016/i.cities.2016.07.003

SISEMA. Sistema Estadual de Meio Ambiente e Recursos Hídricos.IDE- SISEMA. Portal de dados geográficos. Minas Gerais, 2015a. Disponível em: <http://geosisemanet.meioambiente.mg.gov.br/>. Acesso em: 10 dez. 2015.

TUCCI, C. (2008). Águas urbanas. Estudos Avançados, 22(63), 97112. https://doi.org/10.1590/S0103-40142008000200007

UFMG. Plano Diretor de Desenvolvimento Integrado da Região Metropolitana de Belo Horizonte - PDDI-RMBH. Propostas de Políticas Setoriais, Projetos e Investimentos Prioritários. V.1. Belo Horizonte: UFMG, 2011.

UFMG. Plano Metropolitano - Macrozoneamento RMBH. Produto 1: Marco teórico metodológico e definição das áreas temáticas afetas ao interesse metropolitano. Belo Horizonte, fev. 2014(a).

UFMG. Plano Metropolitano - Macrozoneamento RMBH. Produto 4: Definição das Zonas de interesse Metropolitano. Belo Horizonte, set. 2014(b).

ZUCARELLI, M.C.; LOPES, F.W.A.; OJIMA, R. Monitoramento das ações em saneamento básico e vulnerabilidade em áreas de risco em Minas Gerais. Conferência Internacional da Rede Waterlat. vol. 1, pp.1-13,2010.

Recebido em: 27/11/2017

Aceito para publicação em: 06/08/2019 